\title{
Experimental definition of microclimatic conditions based on water transfer and porous media properties for the conservation of prehistoric constructions: Cueva Pintada at Galdar, Gran Canaria, Spain
}

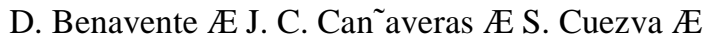 \\ L. Laiz Æ S. Sanchez-Moral
}

Received: 25 October 2007 / Accepted: 6 February 2008 / Published online: 20 February 2008 @ Springer-Verlag 2008

\begin{abstract}
Microclimatic parameters and natural materials were studied in order to assess conservation of the cave complex at Galdar, Gran Canaria. Based on the microclimatic data, experimental simulations were carried out to quantify water retention capacity and water vapour transport kinetics under continuously changing extreme temperatures and relative humidity values. The behaviour of natural construction materials is greatly influenced by changes in thermo-hygrometric conditions and is linked to pore structure. The host rock has a complex porous media: high porosity and polymodal pore size distribution, where the smallest pores contribute to water condensation, whilst large pores lead to high water absorption rates. The axial compressive strength of the host-rock decreases between 30 and $70 \%$ at water saturation. Stuccos covering cave wall paintings are formed by clay minerals, mainly smectites. These clay minerals cover a large specific surface area, which leads to a high capacity for water condensation and retention. It is also shown that neither water condensation
\end{abstract}

D. Benavente (\&) . J. C. Cañaveras Departamento de Ciencias de la Tierra y el Medio Ambiente, Universidad de Alicante, Ap. 99, 03080 Alicante, Spain e-mail: david.benavente@ua.es

D. Benavente . J. C. Cañaveras Laboratorio de Petrología Aplicada, Unidad Asociada CSIC-UA, Alicante, Spain

S. Cuezva . S. Sanchez-Moral Departamento de Geologı́a, Museo Nacional de Ciencias Naturales, CSIC, Madrid, Spain

L. Laiz Instituto de Recursos Naturales y Agrobiologı́a de Sevilla, CSIC, Sevilla, Spain

nor vapour transport are noticeably modified by the presence of stucco on the host-rock when rapid, highly variable changes occur in environmental conditions if large shrinkage cracks are present. Results show that safe threshold microclimatic conditions can be found below $75 \% \mathrm{RH}$ in the natural temperature range and that slight variations in temperature and relative humidity do not modify durability properties.

Keywords Stone decay . Pyroclastic rocks . Environmental management . Heritage conservation . Water transport properties . Pore structure . Canary Islands

Introduction

Much of our cultural heritage is made from natural porous materials, including rocks and clays. These are often exposed to the environment and may suffer the effects of weathering. Water plays a fundamental role in the phenomena of material decay and its presence favours different decay mechanisms, including salt weathering, freeze-thaw action, hydric swelling, material dissolution and biodeterioration. Moreover, the presence of a film of water may decrease the free surface energy of the material, weakening it (Bell 2000). This is particularly true in rocks, which contain clay minerals, where water may alter the structure of the material, causing swelling, stress and fractures (Jime'nez Gonza'lez and Scherer 2004; Steindlberger 2004; Weiss et al. 2004).

Water retention and transfer properties are related to pore structure and relative humidity, and are governed by different processes. At a very low relative humidity, the pore surface starts to form a single monolayer of $\mathrm{H}_{2} \mathrm{O}$ molecules. The only transport mechanism is vapour 
transport. With rising air humidity, a multilayer of water molecules is developed and surface flow occurs as a secondary and more efficient transport mechanism. The condensation process is mainly produced in pores with a radius lower than $0.1 \mathrm{~lm}$ when the Kelvin effect prevails. At a high relative humidity, capillary forces start to govern the internal liquid flow, which are active in the pore radius range between $0.1 \mathrm{~lm}$ and $1 \mathrm{~mm}$. Finally, saturated liquid flow occurs when the material is completely filled with water and a pressure gradient is applied to the porous media (Rose 1963; Camuffo 1998; Beck et al. 2003; Franzen and Mirwald 2004).

Weathering is favoured by variations in environmental conditions and natural materials undergo changes to reach an equilibrium in accordance with these new environmental conditions. Therefore, cyclic environmental changes are, by far, the most effective scenario for weathering as they lead to continual modifications in the stone's behaviour. At confined sites, such as buildings or hypogeal environments, microclimatic variations are closely linked to the presence of visitors, lighting and ventilation systems, structural restorations and modifications, etc. For example, during each breathing cycle, a person exhale airs that contains more moisture than the air they inhale. Hence, if people enter a building in sufficient numbers they will cause the relative air humidity to rise significantly, particularly if ventilation in building is relatively poor. Other climatic parameters, such as air temperature and $\mathrm{CO}_{2}$ content are also modified by visitors leading to condensation and corrosion problems (Sanchez-Moral et al. 1999).

Microclimatic parameters and natural materials were studied in order to assess conservation of the cave complex at Galdar, Gran Canaria. Cueva Pintada is part of a larger complex of six caves that were excavated by Pre-Hispanic Canarian people in the tuff. The main chamber has a rectangular floor and paintings are to be found on the upper half of the three walls (Fig. 1a). These parts of the walls had been covered with mortars to even out the surface and plastered with clay to prepare the base upon which the
Gran Canaria's weather is mild, with little variation in annual average temperatures. Outside the cave, in the village of Galdar, the average air temperature is $19.9^{\circ} \mathrm{C}$, ranging from 10.9 to $34.3^{\circ} \mathrm{C}$, whilst inside, air temperature ranges from 17.5 to $26.0^{\circ} \mathrm{C}$ (annual average: $21.7^{\circ} \mathrm{C}$ ). The host-rock temperature fluctuates less than air, with values ranging from 19.1 to $23.6^{\circ} \mathrm{C}$ (annual average: $21.5^{\circ} \mathrm{C}$ ). Values of cave relative air humidity range from 38 to $75 \%$. Relative air humidity outside the cave varies from 7 to $100 \%$ reaching maximum values in the autumn/winter period. Rainfall is low and the scarce precipitation does not directly affect the cave.

The aim of this paper is to define experimentally safe microclimatic conditions for the conservation of the prehistoric constructions at Cueva Pintada, based on water transfer and porous media properties. Particular emphasis is placed on the influence of pore structure and relative humidity on both water retention and vapour and liquid transport. The variation of rock strength due to the presence of water is also evaluated. The experimental set-up and tests used have been chosen as they are an excellent means for quantifying the response of materials under highly variable extreme daily climatic conditions; they can be easily performed and interpreted and they also provide the information necessary for the safe management of Cueva Pintada.

Experimental procedures

Materials

The samples studied were collected in different outcrops within the archaeological park, where the succession of pyroclastic beds was well represented. The sampled beds correspond with those upon which the paintings are located inside Cueva Pintada.

\section{3}

Fig.1 a Pre-hispanic paintings on the upper half of one of the walls of Cueva Pintada (painted cave). The decorative elements (red and white in colour) are geometric, forming a symmetrical composition from the central axis of the chamber. $b$ Detail of wall showing remains of red pigments and the stucco (a thin layer of argillaceous material) that was prepared to paint the rock mural was painted (Fig. 1b). The colouring materials were of mineral origin, mainly clays and iron hydroxides (San-chez-Moral
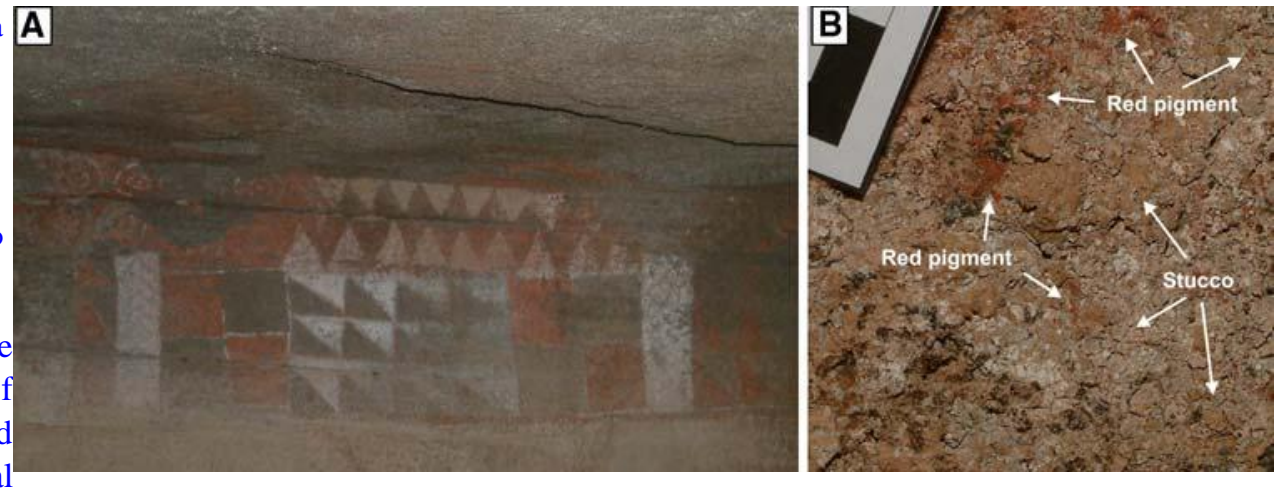
et al. 2002). 
The argillaceous materials used to simulate the prehispanic stucco or plaster in the laboratory tests belong to interlayer clays between pyroclastic beds, whose composition is equivalent to that used to prepare the base for the paintings.

Petrographic and mineralogical studies were carried out by means of optical polarizing microscopy (Zeiss Axioscop) on thin sections and scanning electron microscope (SEM) observation. SEM examination was performed using a Philips XL-20 instrument with an EDAX Super UTW detector (model Philips DX4i). Mineral composition of samples was determined by XRD in a Philips PW-1710 diffractometer. For argillaceous samples, additional analysis of the fraction $163 \mathrm{~mm}$ was performed by preparing oriented aggregates: air-dried, solvated for $48 \mathrm{~h}$ at $110^{\circ} \mathrm{C}$ with ethylene-glycol, and heated for $1 \mathrm{~h}$ at $550^{\circ} \mathrm{C}$.

\section{Porous media}

In order to characterise the porous media of the host rock, mercury intrusion porosimetry (MIP), helium picknometry and the nitrogen absorption technique were used, whilst the pore properties of clays were characterised using only the nitrogen absorption technique.

From MIP, the connected porosity $(\mathrm{P})$, pore volume ( $\mathrm{V}_{\text {pore }}$ ), pore size distribution [calculated from the median pore size $\left(\mathrm{r}_{\mathrm{m}}\right)$ ] and specific surface area (SSA) were all obtained using an Autopore IV 9500 Micrometrics mercury porosimeter (Table 1). The pore size interval characterisation by MIP ranges from 0.002 to $200 \mathrm{~lm}$, which

\begin{tabular}{|c|c|}
\hline Volcanic host-rock & \\
\hline Connected porosity, $\mathrm{P}(\mathrm{Hg})(\%)$ & $28.08 \pm 3.22$ \\
\hline Mean radius, $\mathrm{rm}(\mathrm{Hg})(\mathrm{lm})$ & $3.12 \pm 1.32$ \\
\hline Specific surface area, $\mathrm{S}(\mathrm{Hg})\left(\mathrm{m}_{2} / \mathrm{g}\right)$ & $12.61 \pm 1.80$ \\
\hline Pore volume, $\mathrm{V}_{\mathrm{P}}(\mathrm{Hg})\left(\mathrm{cm}_{3} / \mathrm{g}\right)$ & $0.19 \pm 0.07$ \\
\hline Specific surface area, SвET $\left(\mathrm{m}_{2} / \mathrm{g}\right)$ & $76.93 \pm 6.87$ \\
\hline Pore volume, $\mathrm{VP}_{\mathrm{P}}\left(\mathrm{N}_{2}\right)\left(\mathrm{cm}_{3} / \mathrm{g}\right)$ & $0.06 \pm 0.01$ \\
\hline Bulk density, $\mathrm{qb}\left(\mathrm{g} / \mathrm{cm}_{3}\right)$ & $1.61 \pm 0.21$ \\
\hline True density, $\mathrm{q}_{\mathrm{t}}(\mathrm{He})\left(\mathrm{g} / \mathrm{cm}_{3}\right)$ & $2.68 \pm 0.01$ \\
\hline Total porosity, Рт (\%) & $36.24 \pm 1.48$ \\
\hline Capillary absorption coefficient, $\mathrm{C}\left(\mathrm{kg} / \mathrm{m}_{2} \mathrm{~h}_{1 / 2}\right)$ & $26.62 \pm 4.00$ \\
\hline Point load strength index, Is (50) (Mpa) & $0.16 \pm 0.05$ \\
\hline $\begin{array}{l}\text { Calculated uniaxial compressive strength, rc } \\
\text { (Mpa) }\end{array}$ & $1.63 \pm 0.52$ \\
\hline Compressional wave velocity, vP $(\mathrm{m} / \mathrm{s})$ & $840 \pm 92$ \\
\hline Argillaceous stucco & \\
\hline Specific surface area, $\mathrm{SBET}_{\text {BET }}\left(\mathrm{m}_{2} / \mathrm{g}\right)$ & $177.43 \pm 24.33$ \\
\hline Pore volume, $\mathrm{VP}_{\mathrm{P}}\left(\mathrm{N}_{2}\right)\left(\mathrm{cm}_{3} / \mathrm{g}\right)$ & $0.13 \pm 0.01$ \\
\hline Sealed toba without stucco & $\begin{array}{l}\text { Sealed toba } \\
\text { with stucco }\end{array}$ \\
\hline $\begin{array}{l}\text { Dc }(g / m 2 h) D e \\
(g / m 2 h)\end{array}$ & $14.60-12.75$ \\
\hline
\end{tabular}

Table 1 Physical properties of the volcanic host-rock and stucco

corresponds, respectively, to the highest and lowest head pressures.
The nitrogen absorption technique was used to complete the micro-mesopore analysis by using an Autosorb-6 Quantachrome apparatus. The pore analysis was described in terms of pore size distribution, pore volume and specific surface area (Table 1). The determination of the SSA was carried out through the BET method in the relative pressure interval $\mathrm{P} / \mathrm{P}_{0}=0.05-0.2$. The pore size distribution was obtained in the $0.0009-0.015 \mathrm{~lm}$ pore-size (radius) interval using the non-local density functional theory for $\mathrm{N}_{2}$ at $77 \mathrm{~K}$ on silica.

Total porosity $\left(\mathrm{PT}_{\mathrm{T}}\right)$ was calculated as follows:

$$
\begin{aligned}
& \mathrm{qb} \\
& \text { Pт ठ\% } \% 1 / 41-\times 100 ; \text { ठ1P qt }
\end{aligned}
$$

where $\mathrm{qt}_{\mathrm{t}}$ is the true density, which is defined as the ratio of its mass to solid volume. Total porosity includes open porosity and closed porosity. Open porosity is the volume of pores accessible to any given molecule, and closed porosity is the volume of isolated pores dispersed over the medium. It is important to mention here that connected porosity is the volume of pores accessible to a given molecule and depends on the technique used. Consequently connected porosity is a fraction of the total open porosity. The true density was obtained using an AccuPyc 1330 Helium pyknometer. The dry bulk density, qbulk, of a rock is defined as the ratio of its mass to its volume, including the volume of voids and grains (Table 1).

\section{Capillary imbibition}

Major sources of water uptake are capillary uprise from the ground, rainfall, wind-driven water or spout water (Franzen and Mirwald 2004). Capillary transport is an important flow mechanism as regards rock-host conservation. Water absorbed by imbibition is capillary water.

The water absorption by capillarity test was carried out using a continuous data-recording device. The balance device was linked to a computer, which automatically records weight gain in the tested specimen at specified (B)

intervals (every $10 \mathrm{~s}$ in this study) using the code CK.It allows automatic monitoring of water uptake in the sample when its lower surface is in contact with the water reservoir. The continuous absorption method permits an extremely accurate characterisation of building materials

h 0.5

with high absorption rates (C $\left[10 \mathrm{~kg} / \mathrm{m}^{2}\right)$, such as, for example, the studied volcanic tuffs (Benavente et al. 2007). The results were plotted as absorbed water per area of the sample throughout imbibition versus the square root of time. Through this kind of representation, the capillary imbibition kinetic shows two parts. The first part defines 
123 
capillary absorption whilst the second part defines saturation. The slope of the curve during capillary absorption is the capillary absorption coefficient, $\mathrm{C}$ (Table 1).

This flow mechanism can be quantified by the water absorption coefficient, $\mathrm{C}$, which is very much linked to the characteristics of both pore structure and the fluid (Dullien et al. 1977; Hammecker and Jeannette 1994; Benavente et al. 2002) and is also related to the square root of permeability, C Hk (Zimmerman and Bodvarsson 1991; Benavente et al. 2007).

\section{Water retention (adsorption-desorption) curve}

The maximum moisture content of the host rock and clays at different relative humidities, long exposure time and constant temperature (isothermal equilibrium conditions) were achieved through the adsorption curve. Samples were previously dried in an oven at $105^{\circ} \mathrm{C}$ for $48 \mathrm{~h}$ and placed in desiccators, in atmospheres of different relative humidities maintained by saturated salt solutions (Table 2). The temperature throughout the experiment was constant $(20 \pm$ $\left.1^{\circ} \mathrm{C}\right)$ and similar to natural conditions $\left(21.5^{\circ} \mathrm{C}\right)$. Samples were weighed at regular intervals. The time elapsed time to reach equilibrium depended on relative humidity: approximately a week for low relative humidity and 6-8 weeks for high relative humidity. The adsorption curve was plotted as the mass of water adsorbed per unit of dried sample $(\mathrm{Dm} / \mathrm{m} 0)$ versus relative humidity.

\section{Vapour transport kinetics}

Vapour transfer kinetics and water content under highly variable daily climatic conditions were studied in the tuff. Their lateral surfaces were sealed using paraffin wax to aid water transfer in one dimension. Thus, vapour movement is produced in similar conditions to those in the cave wall. The influence of stucco clay on the vapour transfer was also evaluated. A decrease in vapour diffusion due to the presence of the stucco may cause water to be accumulated in the stucco-tuff interface, and could consequently lead to a catastrophic deterioration in the paintings. Finally, the stability of the stuccos was evaluated over 864 experiment hours under highly variable daily climatic conditions.

The lateral surfaces of the dried samples were sealed using paraffin wax (Productos Promade, SA). For this purpose, paraffin was heated to a liquid state and then spread over the rock to form a thick homogeneous layer.

Vapour transfer kinetics and the water content of samples were measured by recording sample mass change. Thus, sealed samples were placed on a BP3100S Sartorius balance (with $0.01 \mathrm{~g}$ resolution), which is housed in a Vo"tsch VC4033 environmental cabinet. The balance device is linked to a computer, which automatically records weight gain in the tested specimen at specified intervals

(every $10 \mathrm{~s}$ in this study) using the code CK. In each temperature and relative humidity $(\mathrm{RH})$ cycle, two stages can be distinguished: the 12 daytime hours $\left(35^{\circ} \mathrm{C}\right.$ and $\left.40 \% \mathrm{RH}\right)$ and the 12 nighttime hours $\left(15^{\circ} \mathrm{C}\right.$ and $\left.90 \% \mathrm{RH}\right)$, with a changeover period between stages of $* 30 \mathrm{~min}$. These environmental conditions were chosen according to the main microclimatic parameters of the cave. An environ

mental sensor (HOBOH8-Pro) was also placed in the chamber in order to control the stability of the environmental conditions.

The vapour water transfer was quantified by means of the coefficient of diffusion, $\mathrm{D}\left(\mathrm{g} / \mathrm{m}^{2} \mathrm{~h}\right)$, defined here as the water content per area of the sample throughout vapour flow occurs versus time. Three temperature and relative humidity cycles were carried out in order to obtain the coefficient of diffusion and water content of the three sealed host-rocks. Stucco was applied to the sealed tuff used in the previous experiment. An argillaceous mixture (mud) was prepared from argillaceous deposits located between the pyroclastic beds. The mud was applied to the previously dampened non-sealed tuff surface and spread over the rock surface to form a thick homogeneous layer of 1-2 mm, similar to the base upon which the mural had been painted. Samples were placed in desiccators with Si-gel over 3 days to obtain a slow and gradual drying at a constant temperature.

Finally, the stability of the stuccos on the tuff was estimated by observing the stuccos over 36 days $(864 \mathrm{~h})$ under highly variable daily climatic conditions.

\section{Rock strength}

In order to estimate the rock strength of the host rock, point load strength and sonic velocity tests were carried out. Point load testing is used to determine rock strength indexes in geotechnical practice. The point load test is an accepted rock mechanics testing procedure used for the

Table 2 Equilibrium relative humidity for different saturated salt solutions at $25^{\circ} \mathrm{C}$ (Wexler 1994)

Saturated salt solutions $\mathrm{Si}$-gel $\mathrm{CaCl}_{2} .6 \mathrm{H}_{2} \mathrm{O} \mathrm{K}_{2} \mathrm{CO}_{3} .2 \mathrm{H}_{2} \mathrm{O} \mathrm{Mg}$ $\left(\mathrm{NO}_{3}\right)_{2} .6 \mathrm{H}_{2} \mathrm{O} \mathrm{NaCl} \mathrm{KCl} \mathrm{KNO} 3 \mathrm{KH}_{2} \mathrm{PO}_{4} \mathrm{H}_{2} \mathrm{O}$

RH(\%) 729435375859396100

\section{3}


calculation of a rock strength index. It may also be used to predict other rock strength parameters with which it is correlated, for example, uniaxial compressive strength. The block test was used, where rock geometry is prismatic with a height/width ratio of between 0.3 and 1.0, preferably closer to 1.0 as suggested by ISRM (1985). The load is then gradually applied to the rock specimen at a constant rate such that failure occurs within 10-60 s. The point load test allows the determination of the uncorrected point load strength index. It must be corrected to the standard equivalent diameter of $50 \mathrm{~mm}$. The procedure for size correction can be obtained graphically or mathematically as outlined by the ISRM procedures. The corrected point load strength index [Is(50)] may be related with uniaxial compressive strength (rc) through a linear equation as follows:

\section{rC $1 / 4 \mathrm{~A}$. Is $050 \mathrm{P} ;$ ¿ $2 \mathrm{P}$}

where the coefficient A depends basically on rock strength. For example, this coefficient may range from 20 to 25 for medium-high rock strength (e.g. granite and marbles) and 10-15 for soft rocks (e.g. low-cemented sandstones) (Romana 1996). In this paper, we estimate uniaxial compressive strength, a parameter, which is more widely accepted than point load strength, using a coefficient of ten due to the low strength of the host rock (Table 1). The estimation of rock strength using the point load test offers a practical advantage in heritage conservation tasks, where it is sometimes difficult to obtain specimens that are large enough to prepare standard test samples for the uniaxial compressive test. Point load strength was obtained for both dry and water saturated host rocks in order to evaluate the variation of rock strength by the water presence.

In order to complete the rock strength characterisation, compressional wave velocity, $\mathrm{VP}$, was measured on the dried samples used in the point load test (Table 1), using the transmission method, which consists of two piezoelectric sensors coupled to the sample at constant pressure. One of the transducers was stimulated using an ultrasonic pulser and the other was used as a receptor sensor. A viscoelastic couplant was used to achieve a good coupling between the transducer and the sample. A Panametric-NDT 5058PR pulser was used to stimulate the emitting transducers whilst a Tektronix-TDS 3012B oscilloscope enabled the acquired digitalized waveform to be displayed, manipulated and stored. Compressional waves were measured using low frequency transducers $(54 \mathrm{kHz})$ due to the strong attenuation of the wave signal generated by the microstructural properties of the rock including large pores, high porosity values and clay minerals. These textural properties produce reflections, scattering, absorption and frictional dissipation of energy, and consequently, an overall attenuation of waveform energy.
Isolation and characterization of microorganisms

Samples collected from the host-rock and stuccos were inoculated on different media: Trypticase Soy-Agar (TSA); TSA supplemented with $\mathrm{NaCl}(3 \%)$ and $\mathrm{MgSO}_{4} .7 \mathrm{H}_{2} \mathrm{O}(2 \%)$; stach-casein and malt-agar. Incubation was carried out at $28^{\circ} \mathrm{C}$ and isolation followed standard microbiological procedures (Laiz et al. 2003).

Molecular techniques were used for the detection of microorganisms and the $16 \mathrm{~S}$ ribosomal RNA gene (16S rRNA) was used to identificy of bacteria. DNA was amplified using PCR and bacterial 16S rRNA genes were amplified using the primer pair $616 \mathrm{~F}\left(5^{\circ}\right.$-AGA GTT TGA TYM TGG CTC AG) and 1510R ( $5^{\circ}$-GGT TAC CTT GTT ACG ACT T) (Gonzalez and Saiz-Jimenez 2004).

Amplification protocols involved one denaturation cycle at $95^{\circ} \mathrm{C}$ for 2 min, followed by 35 denaturation cycles of $15 \mathrm{~s}$ at $95^{\circ} \mathrm{C}$, annealing at $55^{\circ} \mathrm{C}$ for $15 \mathrm{~s}$ and elongation at $72^{\circ} \mathrm{C}$ for $2 \mathrm{~min}$, with a final elongation cycle at $72^{\circ} \mathrm{C}$ for $10 \mathrm{~min}$. Amplifications were performed in a BioRad iCycler iQ thermal cycler (BioRad, Hercules, CA) and PCR products were purified and sequenced by SECUGEN Sequencing Services (CSIC, Madrid, Spain). Sequence data was edited using the Chromas 1.45 software (Technelysium, Tewantin, Australia). Homology searches with these sequences were performed using the Blast algorithm (Altschul et al. 1990)on the NCBI database (http://www.ncbi.nlm.nih.org/blast/).

\section{Results and discussion}

The host-rock in Galdar archaeological park is made up of pyroclastic beds (lapilli tuff) with interbedded epiclastic deposits. The pyroclastic deposits are composed of 10-40 $\mathrm{cm}$ thick beds or layers, which correspond to several episodes of explosive volcanism. Epiclastic deposits consist of thin layers of argillaceous material, no more than 5-10 $\mathrm{cm}$ thick, which correspond to alluvial and weathering phases between volcanic episodes. The pyroclasts are tephritic and/ or basanitic in composition and show porphyritic fabrics with phenocrysts embedded in a glassy to cryptocrystalline matrix (Fig. 2a). The most abundant phenocrystals are clinopyroxene, olivine and plagioclase feldspar. These are low to moderate vesiculated pyroclasts (according to Houghton and Wilson 1989) which are altered to varying degrees (Fig. 3a), producing a variety of colours, from dark brown to orange-pale brown when the alteration is more marked. Carbonate minerals (calcite, dolomite) and zeolites (chiefly phillipsite) partially fill both vesicles and pyroclast inter-spaces (Figs. 2, 3). Clay minerals (mainly belonging to the smectite group) also appear in these gaps and, together with zeolites, can be considered as products of pyroclast alteration processes (devitrification) (Fig. 3b). 


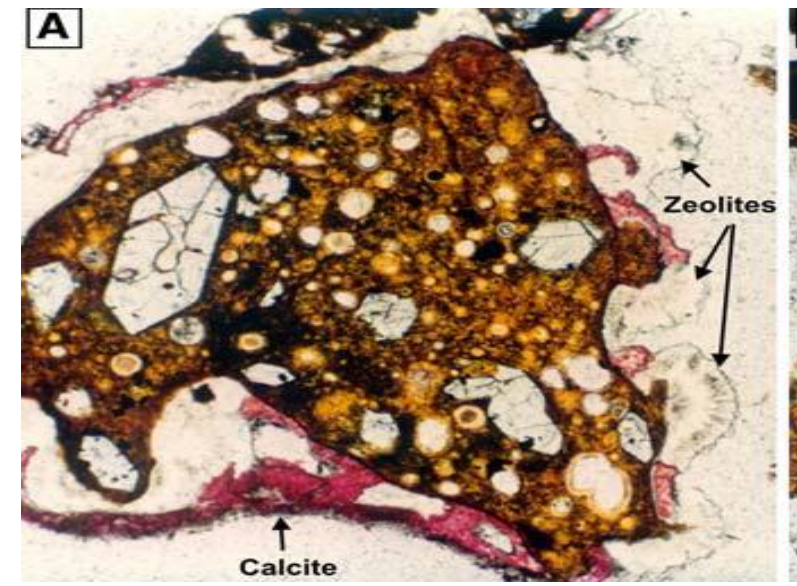

The argillaceous material that forms the epiclastic deposits mainly contains illite $(10-55 \%)$, kaolinite (2$15 \%$ ) and smectite (mainly montmorillonite) (4-12\%). Carbonate minerals are relatively abundant in most of the samples, ranging from 10 to $35 \%$. Feldspar, Fe-oxide, zeolite and gypsum grains are also present in varying amounts (2-10\%).

The expandability of smectites indicates that montmorillonite-rich samples are more likely to suffer mechanical alteration due to the swelling processes caused by condensation mechanisms or by retraction during the drying process. The presence of carbonates can also be harmful for the conservation of paintings if condensation processes occur in relatively $\mathrm{CO}_{2}$-rich atmospheres. also the volume of large and closed pores. In this kind of volcanic rocks, vacuole porosity, which is a closed or non-well connected porosity, may be significant.

\section{3}

Fig. 3 a SEM image of pyroclast showing vacuoles and altered vitreous matrix. b Detail of a showing smectite aggregates formed by the alteration (devitrification) of pyroclast in the wal of vacuoles. c SEM image illustrating inter-pyroclast pores partially filled by carbonate and zeolite cements. $d$ Close-up of zeolite (phillipsite) aggregates

The host rock has a complex porous media: high porosity and polymodal pore size distribution (Fig. 4). It is important to $\mathbf{C}$ mention that a considerable fraction of pore volume was not determined by the mercury intrusion porosimetry method (MIP). The pore size interval characterisation by MIP ranges from 0.002 to $200 \mathrm{~lm}$, and 5 Proclaste consequently, underestimates total porosity (Table 1). Porosity below $0.0021 \mathrm{~m}$ can be completed
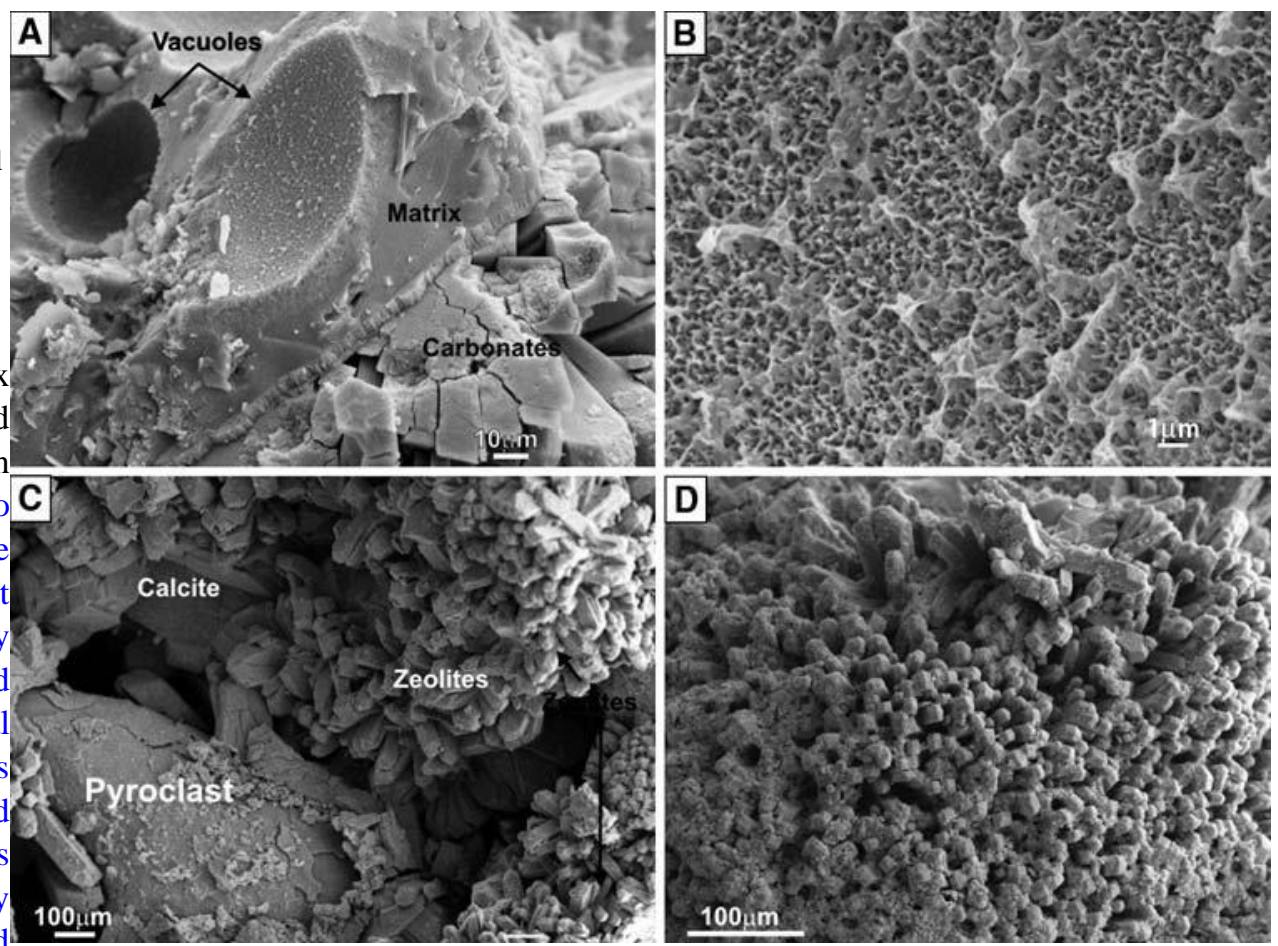
using the nitrogen absorption technique. The fraction of large pores is reflected in the total porosity values, which include not only the pore fraction obtained from nitrogen adsorption and MIP, but 


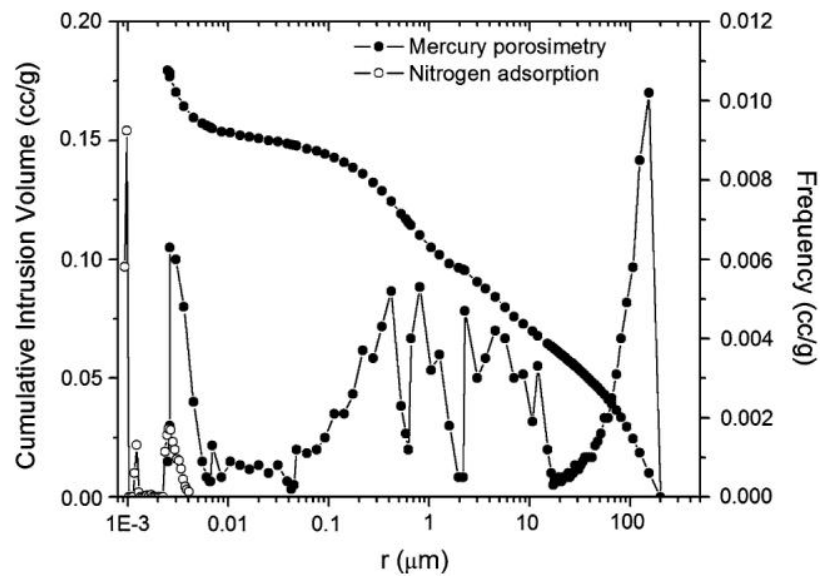

Fig. 4 Cumulative mercury intrusion curve and pore size distribution curves obtained by nitrogen adsorption and mercury intrusion porosimetry for the tuff

SEM images (Figs. 2, 3) illustrate this information regarding size, shape and arrangement of the grains and pores, and show larger pores due to the layout of pyroclasts, partially cemented carbonates and zeolites (Fig. 3c). The smallest pores are described by zeolites, micritic cal-cite and argillaceous minerals (Fig. 3b, d).

The polymodal pore size distribution of the tuff shows a substantial part of the pore spectrum between $0.1 \mathrm{~lm}$ and 1 $\mathrm{mm}$, providing high water absorption rates, as well as a higher pore fraction below $0.1 \mathrm{~lm}$, which is the main cause of capillary condensation. The highly active capillary system (up to about $0.1 \mathrm{~lm}$ ) means that liquid water can easily penetrate the tuff and explains the extraordinarily high values recorded for the capillary imbibition coefficient $1 / 2$

at $26.62 \mathrm{~kg} / \mathrm{m}^{2}$.

The water retention curves obtained in terms of relative humidity are shown in Fig. 5. The maximum moisture content of the host rock and clays at $100 \% \mathrm{RH}$ provides the capacity for water condensation. Both porous materials present active water retention, although clays exhibit the highest moisture uptake values. The amount of adsorptive water uptake correlates mainly with the inner surface area, determined by the $\mathrm{N}_{2}$-BET method (Table 1). Stuccos covering cave wall paintings are formed by clay minerals consisting of smectites, illites and kaolinites. These clay minerals have a high specific surface area $(* 177 \mathrm{~m} / \mathrm{g})$, which provides a high capacity and susceptibility to water condensation and retention compared to the host-rock $(* 77$ $\mathrm{m}^{2} / \mathrm{g}$ ). The relationship between specific surface area and water availability indicates a high bioreceptivity of these natural materials (Sanchez-Moral et al. 2005).

Figure 5 clearly shows that water adsorption increases as relative humidity increases for both the host-rock and the stuccos. The presence of a bend at a relative humidity of about $75 \%$ is due to a change in behaviour in the

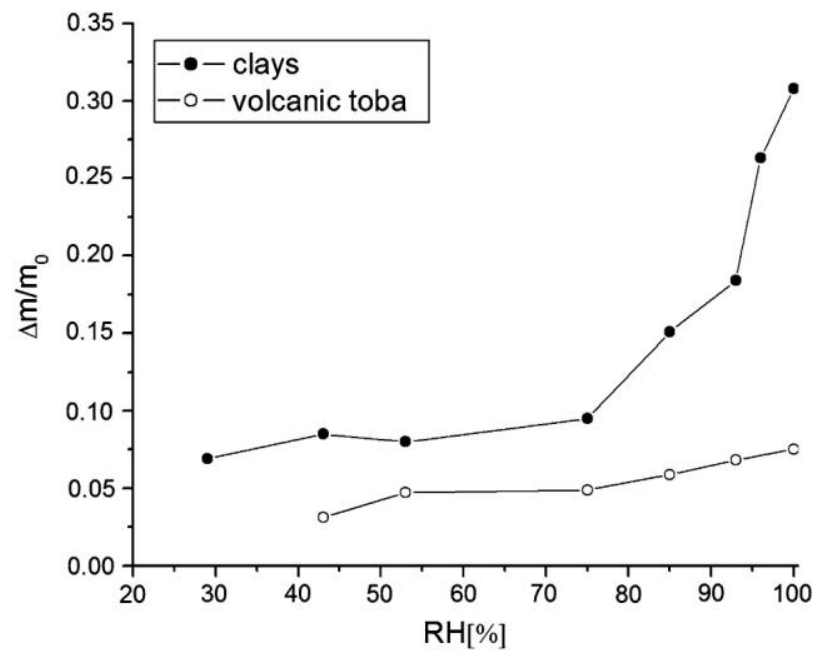

clay minerals

saturation phases. With rising air humidity, the number of layers of water molecules on the pore surface increases. Within this multilayer, capillary forces start to govern the internal flow and vapour transport becomes a less efficient transport mechanism. As a consequence, the studied porous materials begin to adsorb more water. This behaviour is more pronounced in the clays than in the host-rock. Results show that safe threshold microclimatic conditions can be found below $75 \% \mathrm{RH}$ in the natural temperature range, where changes in state and, consequently, in water volume are kept to a minimum.

Eight weeks elapsed in order to reach an equilibrium at $100 \% \mathrm{RH}$ and $20^{\circ} \mathrm{C}$ (similar to natural conditions), by which time both the host-rock and the stuccos were partially covered by a filamentous microbial mat. In laboratory cultures (TSA and malt-agar), a series of bacteria were isolated. Members of the genera Nocardia, Streptomyces, Nocardiopsis, Amycolatopsis, Kocuria, and Arthrobacter of the order of Actinomycetales were isolated. Also, bacteria belonging to the phylum Firmicutes (mainly represented by the genera Bacillus and Ammoniphilus) were identified. These bacteria are aerobic heterotrophic and are generally capable of generating spores. The third bacterial group represented in these cultures is Alpha-Proteobacteria, with members of the Rhizobiales order (Rhizobium and Mesorhizobium). A fungus, Cordyceps sp. was also isolated. The relatively quick appearance of such microorganisms and the compositional complexity of the biofilms developed over 8 weeks prove that a strong increase in air humidity will cause serious damage to the paintings.

Vapour transfer kinetics and water content under highly variable daily climatic conditions were studied in sealed tuffs. Figure 6 compares the variation of weight mass per area in the tuff with and without stucco during three daily

Fig. 5 Water retention curve versus relative humidity of the tuff and 
climatic conditions. The movement of moisture is caused by the water vapour concentration gradient defined in the climatic chamber. During the night stage $\left(15^{\circ} \mathrm{C}\right.$ and $\left.90 \% \mathrm{RH}\right)$, water spread from the area with the most vapour (the chamber) to the Volcanic host-rock

one with less (the rock). Consequently, vapour condenses in Connected porosity, $\mathrm{P}(\mathrm{Hg})(\%)$

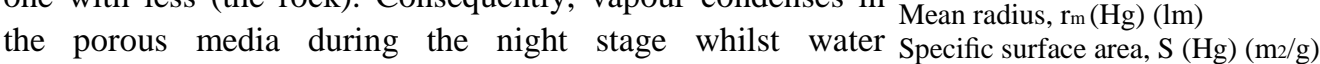

$28.08 \pm 3.22$

$3.12 \pm 1.32$

$12.61 \pm 1.80$

evaporates from the sample during the daytime stage.

Pore volume, $\mathrm{VP}(\mathrm{Hg})\left(\mathrm{cm}_{3} / \mathrm{g}\right)$

$0.19 \pm 0.07$

The vapour transfer is described by means of the coefficient of diffusion, $\mathrm{D}$, and quântifies the diffusive transport in the tested material. This coefficient of diffusion is defined here as a steady-state flux in the pore water per unit surface of porous medium. During each stage of environmental conditions, the vapour flux reaches the steady-state after $* 2 \mathrm{~h}$ (Fig. 6). The coefficient of diffusion during condensation, $\mathrm{D}_{\mathrm{c}}$, and evaporation, $\mathrm{De}$, processes are listed in Table 3.

The results obtained show that no considerable differences are found due to the addition of stucco. Firstly, the coefficient of diffusions during vapour condensation and evaporation processes are similar in each sample.

Secondly, these coefficients are almost identical when the tuff is covered by the stucco. This similarity in vapour transfer could be explained by the presence of large shrinkage cracks in the stucco (Fig. 7), which provide important permeability to vapour. The presence of shrinkage cracks prevents water from being accumulated in the stucco-tuff interface and explains the cave-painting's excellent state of conservation of on the cracked stucco.

Thirdly, the amount of condensed water is also similar in the tuff with and without stucco (Fig. 6). This result shows that stucco clays do not noticeably contribute to water condensation when rapid, highly variable changes in thermo-hygrometric environmental conditions occur. Moreover, as vapour diffusion kinetics through porous materials is slow, the water condensed in the tuff after 12 experiment hours is less $(0.018 \mathrm{~g} / \mathrm{g})$ than after 2 months of exposure time $(0.074 \mathrm{~g} / \mathrm{g})$.

Finally, the stability of the stuccos on the tuff was not modified after 36 days ( $864 \mathrm{~h}$ ) of rapid, highly variable

Fig. 6 Variation of water content per area in the tuff without (a) and with (b) stucco during three daily climatic cycles

Table 3 The coefficients of diffusion for the toba with and without stucco during the condensation, $\mathrm{D}_{\mathrm{c}}$, and evaporation, $\mathrm{De}$, processes

changes in daily climatic conditions. Figure 7 shows the visual appearance of stuccos applied on the tuff before (Fig. 7a) and after the test (Fig. 7b). A binary image of the original photograph has been included to highlight the textural features of the stucco.

The cracked appearance of the stuccos obtained shortly after their application to the tuff, does not vary throughout the experiment. This appearance is very similar to that of the original stuccos on the cave walls (Figs. 1b, 7). The fact that these stuccos have conserved their paintings for hundreds of years under natural conditions is extremely significant.

These important and practical conclusions should be taken into account when evaluating the effect of microclimatic variations on the conservation of paintings, since microclimatic variations coupled with the presence of visitors, lighting and ventilation systems, structural restorations, modifications, etc., to the detriment of this heritage.

The axial compression stress of the dry rock is approximately $2 \mathrm{MPa}$ and this can thus be classified as a very soft rock (ISRM 1981). Results also show that the presence of water plays an important role in rock strength. Between the dry and saturated state, axial compressive strength decreases by between 30 and $70 \%$. Water inside the pore network leads to a great reduction in strength, which could be explained by the decreased contact energy between the grains. Across the whole range of humidity, uniaxial compressive strength strongly decreases as water content increases to a critical water content and then stabilizes near its lower value, i.e. the value at

saturation (Beck et al. 2003). The A

host-rock can become rapidly

\section{3}
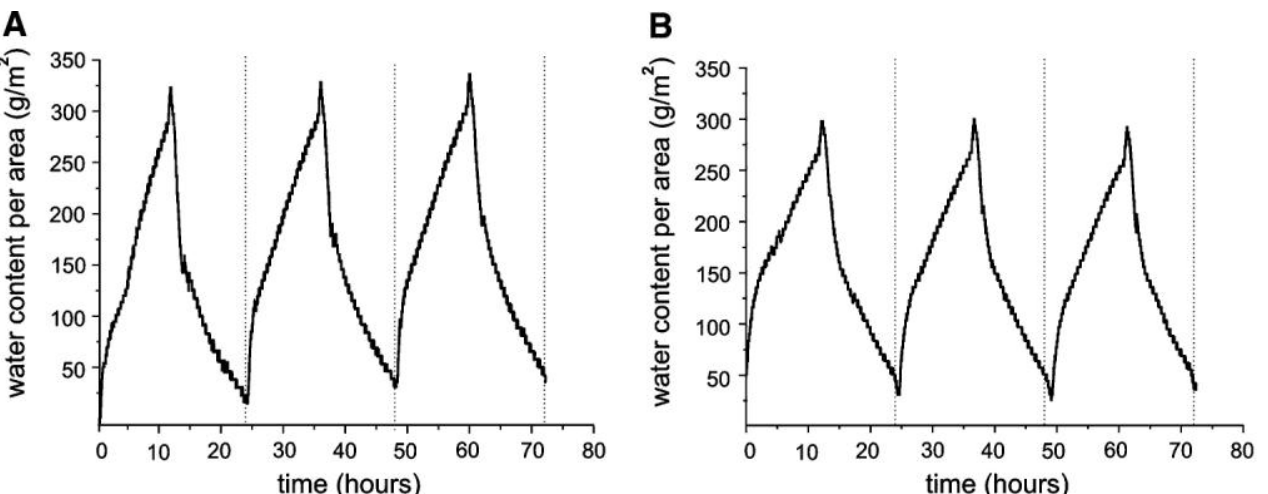

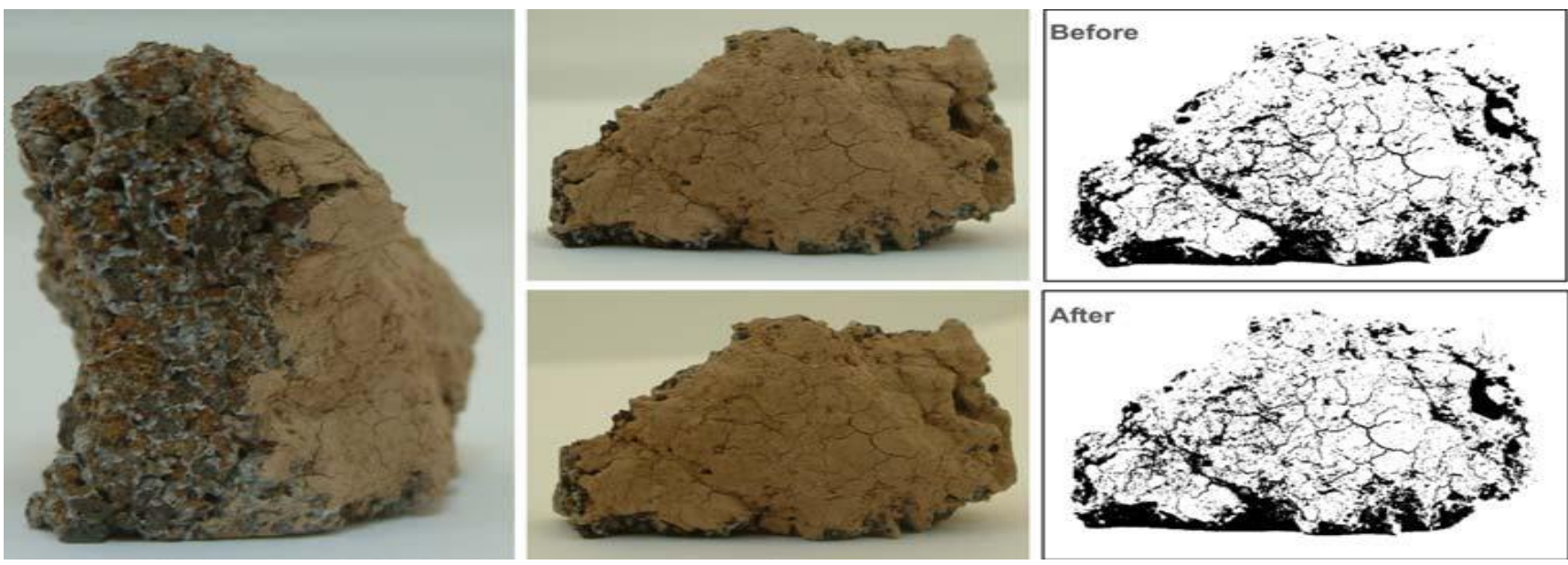

saturated due to its highly active capillary water transfer (Table 1). This fact will lead to a drastic decrease in strength, and will consequently harm all of the paintings.

\section{Conclusions}

In this study, we have determined experimentally safe microclimatic conditions based on water transfer and porous media properties in order to minimize damage to interior stonework. The behaviour of both the host-rock and the stuccos is highly sensitive to changes in thermohygrometric conditions and is also linked to pore structure. The polymodal pore size distribution of the tuff shows a significant pore fraction below $0.1 \mathrm{~lm}$, which is the main cause of capillary condensation and retention. Zeolites (mainly phillipsite), carbonate minerals (calcite, dolomite) and clay minerals (mainly belonging to the smectite group) contribute to this specific pore volume. Moreover, an important fraction of the pores in the tuff range between $0.1 \mathrm{~lm}$ and $1 \mathrm{~mm}$, which means that liquid water can easily penetrate the tuff and also explains the extraordi

$$
{ }_{\mathrm{h}} 1 / 2
$$

narily high values of $26.62 \mathrm{~kg} / \mathrm{m}^{2}$ recorded for the capillary imbibition coefficient. Results also show that the presence of water plays an important role in rock strength. Between the dry and saturated states, axial compressive strength decreases by between 30 and $70 \%$. The highly active capillary water transfer in the host-rock will lead to a drastic decrease in its strength and will consequently harm all of the paintings.

Once the main environmental parameters of the complex had been defined, and in order to identify the optimum microclimatic conditions for the conservation of the host-rock and paintings, a set of experimental simulations were carried out to quantify the water retention capacity and water vapour transport kinetics under highly variable extreme temperatures and relative humidity.

Results show that the presence of stucco does not noticeably contribute to water condensation when rapid, highly variable changes occur in environmental conditions. This similarity in vapour transfer could be explained by the presence of large shrinkage cracks in the stucco, which provide the stucco with important permeability to vapour. The presence of shrinkage cracks prevents water from being accumulated in the stucco-tuff interface and explains the excellent state of conservation of the cave-painting on the cracked stucco. Moreover, the stability of the stuccos on the tuff did not vary after 36 days $(864 \mathrm{~h})$ of extreme variations in daily climatic conditions. However, after the 8 weeks taken to reach equilibrium at $100 \% \mathrm{RH}$ and $20^{\circ} \mathrm{C}$ (similar to natural conditions), both the host-rock and the stuccos were partially covered by a filamentous microbial mat.

For these reasons, we can conclude that the safe threshold microclimatic conditions can be found below $75 \% \mathrm{RH}$ in the natural temperature range, and slight variations in temperature and relative humidity do not modify durability properties. The relatively rapid appearance of microorganisms and the compositional complexity of the biofilms developed proves the serious risk of deterioration that condensation can cause due to an increase in the air humidity above the safe threshold established. We strongly believe that these results make a worthwhile contribution for the safe management of Cueva Pintada, in order to protect these unique ancient paintings for future generations.

Acknowledgments This study was financed by the Cabildo Insular of Gran Canaria, under the framework of the Spanish MEC projects CGL2004-05969/BTE and CGL2006-11561/BTE. This study has been possible thanks to the kind support and help received from the Director (Iñaki Saénz) and all of the staff at the Cueva Pintada de Galdar Museum and Archaeological Park, as regards microclimatic data. The authors are also extremely grateful to Dr. G. Algozzini for her valuable help in the preparation and application of stucco and paraffin on the rock samples. 


\section{References}

Altschul SF, Gish W, Miller W, Myers EW, Lipman DJ (1990) Basic local alignment search tool. J Mol Biol 215:403-410

Beck K, Al-Mukhtar M, Rozenbaum O, Rautureau M (2003) Characterization, water transfer properties and deterioration in tuffeau: building material in the Loire valley-France. Build Environ 38:1151-1162

Bell FG (2000) Engineering properties of soils and rocks. Blackwell Science Oxford, Oxford

Benavente D, Lock P, Garcı́a-del-Cura MA, Ordóñez S (2002) Predicting the capillary imbibition of porous rocks from microstructure. Trans Porous Media 49:59-76

Benavente D, Cueto N, Martinez-Martinez J, Garcı́a-del-Cura MA, Can averas JC (2007) The influence of petrophysical properties on the salt weathering of porous building rocks. Environ Geol 52:197-206

Camuffo D (1998) Microclimate for cultural heritage. Elsevier, Amsterdam

Dullien FAL, El-Sayed MS, Batra VK (1977) Rate of capillary rise in porous media with nonuniform pores. J Colloid Interface Sci 60:497-506

Franzen C, Mirwald PW (2004) Moisture content of natural stone: static and dynamic equilibrium with atmospheric humidity. Environ Geol 46:391-401

Gonzalez JM, Saiz-Jimenez C (2004) Microbial activity in biodeteriorated monuments as studied by denaturing gradient gel electrophoresis. J Sep Sci 27:174-180

Hammecker C, Jeannette D (1994) Modelling the capillary imbibition kinectics in sedimentary rocks: role of petrographical featrures. Trans Porous Media 17:285-303

Houghton BF, Wilson CJN (1989) A vesucarity index for pyroclastic deposits. Bull Volcanol 51:451-462

ISRM (1981) Rock characterisation. Testing and monitoring. ISRM suggested methods. In: Brown ET (ed) Commission on testing and monitoring. International Society for Rock Mechanics. Pergamon Press, New York

ISRM (1985) International Society of Rock Mechanics Commission on testing methods, suggested method for determining point load strength. Int J Rock Mech Min Sci Geomech Abstr 22:51-60 Jime'nez Gonza'lez I, Scherer GW (2004) Effect of swelling inhibitors on the swelling and stress relaxation of clay bearing stones. Environ Geol 46:364-377

Laiz L, Gonzalez JM, Saiz-Jimenez C (2003) Microbial communities in caves: Ecology, physiology, and effects on paleolithic paintings. In: Koestler RJ, Koestler VR, Charola AE, Nieto-Fernandez FE (eds) Art, biology, and conservation: biodeterioration of works of art. The Metropolitan Museum of Art, New York, pp 210-225

Romana (1996) El ensayo de compresión puntual de Franklin. Ingenier'́a Civil 102:116-120

Rose DA (1963) Water movement in porous materials - II: the separation of the components of water movement. Br J Appl Phys 14:491-496

Sanchez-Moral S, Soler V, Canaveras JC, Sanz-Rubio E, Van Grieken R, Gysels K (1999) Inorganic deterioration affecting the Altamira Cave, N Spain: quantitative approach to wall-corrosion (solutional etching) processes induced by visitors. Sci Total Environ 244:67-84

Sanchez-Moral S, Garcia-Guinea J, Sanz-Rubio E, Cañaveras JC, Onrubia-Pintado J (2002) Mortars, pigments and saline efflorescence from Canarian pre-Hispanic constructions (Galdar, Grand Canary Island). Constr Build Mater 16:241-250

Sanchez-Moral S, Luque L, Cuezva S, Soler V, Benavente D, Laiz L, Gonzalez JM, Saiz-Jimenez C (2005) Deterioration of building materials in Roman catacombs: the influence of visitors. Sci Total Environ 349:260-276

Steindlberger E (2004) Volcanic tuffs from Hesse (Germany) and their weathering behavior. Environ Geol 46:378-390

Weiss T, Siegesmund S, Kirchner D, Sippel J (2004) Insolation weathering and hygric dilatation: two competitive factors in stone degradation. Environ Geol 46:402-413

Wexler A (1994) Constant humidity solutions. In: Lide DR (ed) Handbook of chemistry and physics, 74th edn. CRC Press, Inc., Boca Raton, p 15

Zimmerman RW, Bodvarsson G (1991) A simple approximate solution for horizontal infiltration in a Brooks-Corey medium. Trans Porous Media 6:195-205 